\title{
Sex Difference in the Inhibitory Effect of Aspirin on Prostacyclin Production of Rat Aortae
}

\author{
Masako MORIKAWA, Takashi KOJIMA, Michiko INOUE \\ and Minoru TSUBOI \\ Department of Pharmacology. Tokyo College of Pharmacy, \\ Hachioji, Tokyo 192-03, Japan \\ Accepted January 5, 1984
}

\begin{abstract}
The effect of aspirin on the prostacyclin $\left(\mathrm{PGI}_{2}\right)$ production of rat aorta was investigated, and the influence of sex hormones on the effect of aspirin was studied by the treatments of hormone administration, ovariectomy and castration. There was no significant sex difference in the arterial production of $\mathrm{PGI}_{2}$ between male and female rats. However, the $\mathrm{PGI}_{2}$ production was decreased with aspirin treatment, and the effect of aspirin was more efficient in male rats. The inhibitory effect of aspirin was reduced in the rats treated with estradiol and the castrated male rats, but it was potentiated in the rats treated with testosterone and the ovariectomized female rats. These results suggest that sex hormones may regulate the effect of aspirin on the $\mathrm{PGI}_{2}$ production in the aorta.
\end{abstract}

Aspirin has been reported to be an effective antithrombotic agent in clinical trials $(1-3)$ and in animal experiments (4). However, the antithrombotic effect of aspirin was found to be more effective in males than in females $(2,4)$.

That effect of aspirin is attributed to its inhibitory effect on $\mathrm{PGI}_{2}$ synthesis; aspirin is considered to acetylate cyclooxygenase, an enzyme involved in $P G s$ synthesis $(5,6)$. $\mathrm{PGI}_{2}$ is the main product of the PGs in aorta (7). Chang et al. $(8,9)$ reported that estradiol stimulated the $\mathrm{PGI}_{2}$ production in cultured smooth muscle cells of rat aorta and promoted the $\mathrm{PGI}_{2}$ production in intact rats. Nakao et al. (10) showed that testosterone suppressed the $\mathrm{PGI}_{2}$ production in cultured rat aortic smooth muscle cells.

In this report, the sex difference in the effect of aspirin and the influence of sex hormones in the inhibitory effect of aspirin on $\mathrm{PGI}_{2}$ production were investigated.

\section{Materials and Methods}

Materials: Aspirin was obtained from Sanko Seiyaku Kogyo Co. Ltd., testosterone (4-androsten-17 $\beta$-ol-3-on) and estradiol (1. 3,5 -Oestratrien-3.17 $\beta$-diol) from Fluka $A G$.
ADP and arachidonic acid from Sigma, and $\left[{ }^{3} \mathrm{H}\right]$-arachidonic acid $(78 \mathrm{Ci} / \mathrm{mmol})$ and $\left[{ }^{3} \mathrm{H}\right]$-6-keto-prostaglandin $\mathrm{F}_{1 a} \quad(120 \mathrm{Ci} /$ $\mathrm{mmol}$ ) from New England Nuclear. $\mathrm{PGI}_{2}$ and $\mathrm{PGH}_{2}$ were given by Ono Yakuhin Kogyo Co. Ltd.

Animals: Wistar strain rats of both sexes were used for this study. At 6 weeks of age, the female rats were anesthetized with ether and then bilaterally ovariectomized via the back route. The male rats were anesthetized with ether and then bilaterally castrated via the ventral route. All rats were housed in a temperature-controlled room with a fixed lighting schedule (a.m. 7:00-p.m. 7:00) and allowed free access to standard laboratory food (Oriental Yeast Co. Ltd.) and water.

Administration of sex hormones: Testosterone or estradiol was dissolved in corn oil. Three days after the operation, the rats were treated with either $5 \mathrm{mg} / \mathrm{kg}$ testosterone or $10 \mu \mathrm{g} / \mathrm{kg}$ estradiol at intervals of three days from 6 weeks to 10 weeks. Control rats were given $1.0 \mathrm{ml} / \mathrm{kg}$ corn oil at the same interval from 6 weeks to 10 weeks.

Drug: Aspirin was suspended in $0.1 \%$ carboxymethylcellulose sodium salt solution for the p.o. administration. The dose levels 
were 20,50 and $100 \mathrm{mg} / \mathrm{kg}$.

Preparation of aortic tissues: At an hour after administration of aspirin, the animals were sacrified by bleeding from common carotid arteries, and the thoracic aortae were quickly isolated and kept in Krebs-Ringer Bicarbonate buffer ( $\mathrm{pH} 7.4$ ).

Measurement of $\mathrm{PGI}_{2}$ production: The aortae were incubated in $50 \mathrm{mM}$ Tris $\mathrm{HCl}$ buffer $(\mathrm{pH} 7.4)$ at $22^{\circ} \mathrm{C}$ for $2,5,10,15,20$ and $30 \mathrm{~min}$. The production of endogenous $\mathrm{PGI}_{2}$ was determined by the modified method of Harada et al. (11, 12). The aorta was mechanically stimulated before each incubation by holding the strip with two forceps and gently stretching the strip ten times within $20 \mathrm{sec}$. The amounts of $\mathrm{PGI}_{2}$ released in the medium were immediately bioassayed as the inhibitory activity against ADPinduced human platelet aggregation (13). The amount of $\mathrm{PGI}_{2}$ increased timedependently for the first $10 \mathrm{~min}$ and then decreased, so the aortae were incubated for $10 \mathrm{~min}$. The content of $\mathrm{PGI}_{2}$ was expressed as $\mathrm{ng} / \mathrm{mg}$ of wet tissue, using synthetic $\mathrm{PGI}_{2}$ as the standard.

Measurement of $\mathrm{PGI}_{2}$ production from exogenous arachidonic acid: The aortae were incubated in Tris $\mathrm{HCl}$ buffer containing 1.0 $\mu \mathrm{g} / \mathrm{ml}$ arachidonic acid at $37^{\circ} \mathrm{C}$ for $2 \mathrm{~min}$. The $\mathrm{PGI}_{2}$ production was immediately determined as described under "Measurement of $\mathrm{PGI}_{2}$ production".

Measurement of $\mathrm{PGI}_{2}$ production with addition of $\mathrm{PGI}_{2}$ as a substrate: The aortae were incubated in Tris $\mathrm{HCl}$ buffer containing $0.5 \mu \mathrm{g} / \mathrm{ml} \mathrm{PGH}$ at $37^{\circ} \mathrm{C}$ for $2 \mathrm{~min}$. The $\mathrm{PGI}_{2}$ production was determined by the abovedescribed method of bioassay.

Determiniation of 6 -keto- $\mathrm{PGF}_{1 \alpha}$ production from $\left[{ }^{3} \mathrm{H}\right]$-arachidonic acid: The aortae were incubated in Tris $\mathrm{HCl}$ buffer containing $2 \mu \mathrm{Ci}\left[{ }^{3} \mathrm{H}\right]$-arachidonic acid at $37^{\circ} \mathrm{C}$ for $20 \mathrm{~min}$. $\mathrm{PGI}_{2}$ was assayed as its hydrolysis product, 6 -keto-PGF $F_{1 \alpha}$. The radioactivity of 6 -keto-PGF - $_{1}$ was determined by the modified method of Sun et al. (14).

Measurement of $\mathrm{PGI}_{2}$ production after addition of aspirin in vitro: The aortae were preincubated with aspirin $(2.0,4.0,6.0$ and $10.0 \mu \mathrm{g} / \mathrm{ml})$ in Tris $\mathrm{HCl}$ buffer $(1.0 \mathrm{ml} / 2.5$ $\mathrm{mg}$ tissue) at $22^{\circ} \mathrm{C}$ for $10 \mathrm{~min}$ and rinsed with Tris $\mathrm{HCl}$ buffer. Then they were incubated in Tris $\mathrm{HCl}$ buffer at $22^{\circ} \mathrm{C}$ for $10 \mathrm{~min}$, and this incubation medium was measured for the $\mathrm{PGI}_{2}$ production as described under "Measurement of $\mathrm{PGl}_{2}$ production". In the study of interaction of aspirin with sex hormones, $1.0 \mu \mathrm{g} / \mathrm{ml}$ testosterone and 1.0 $\mathrm{ng} / \mathrm{ml}$ estradiol were used. The aortae were preincubated with aspirin $(6 \mu \mathrm{g} / \mathrm{ml})$ and testosterone or estradiol in Tris $\mathrm{HCl}$ buffer $\left(1.0 \mathrm{ml} / 2.5 \mathrm{mg}\right.$ tissue) at $22^{\circ} \mathrm{C}$ for $10 \mathrm{~min}$.

\section{Results}

Effect of aspirin on $\mathrm{PGI}_{2}$ production from endogenous arachidonic acid

Figure 1 shows the inhibitory effect of aspirin on the $\mathrm{PGI}_{2}$ production. In the control group, no sex difference was found in the $\mathrm{PGI}_{2}$ production. In aspirin-treated group, the $\mathrm{PGI}_{2}$ production was decreased in a dosedependent manner. Aspirin at a dose $20 \mathrm{mg} /$ $\mathrm{kg}$ did not efficiently decrease the $\mathrm{PGI}_{2}$ production in female rats. Aspirin at a dose $50 \mathrm{mg} / \mathrm{kg}$ significantly decreased the $\mathrm{PGI}_{2}$ production and more significantly decreased it in male rats. Furthermore, aspirin at $100 \mathrm{mg} /$ $\mathrm{kg}$ completely inhibited the $\mathrm{PGI}_{2}$ production

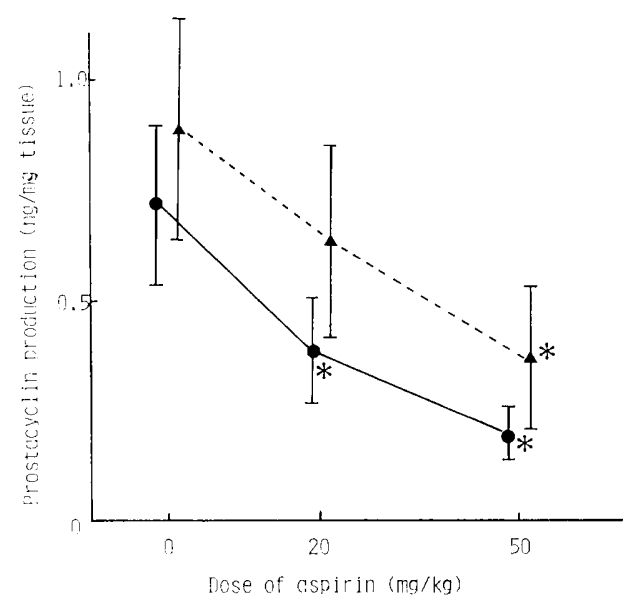

Fig. 1. Effect of aspirin on prostacyclin production from male and female rat aortae. Thoracic aortae were obtained from rats an hour after treatment with aspirin. The $\mathrm{PGI}_{2}$ after stretch-stimulation of the aortae was determined by the platelet aggregation method. Mean \pm S.D. $(n=8)$. ${ }^{*} P<0.05$ : Significant difference from the control value for each sex. male, $\boldsymbol{\Delta}$ : female. 
in both sexes of rats (data not shown).

Effect of aspirin on $\mathrm{PGI}_{2}$ production from exogenous arachidonic acid

Figure 2 shows that aspirin inhibited the $\mathrm{PGI}_{2}$ production with the addition of arachidonic acid as a substrate. In the control group, there was no significant sex difference in the $\mathrm{PGI}_{2}$ production, but the $\mathrm{PGI}_{2}$ production in females was slightly larger than in males. In the aspirin-treated group, aspirin dose-dependently decreased the $\mathrm{PGI}_{2}$ production. These results agree with those on the $\mathrm{PGI}_{2}$ production from endogenous arachidonic acid. The effect of aspirin was more

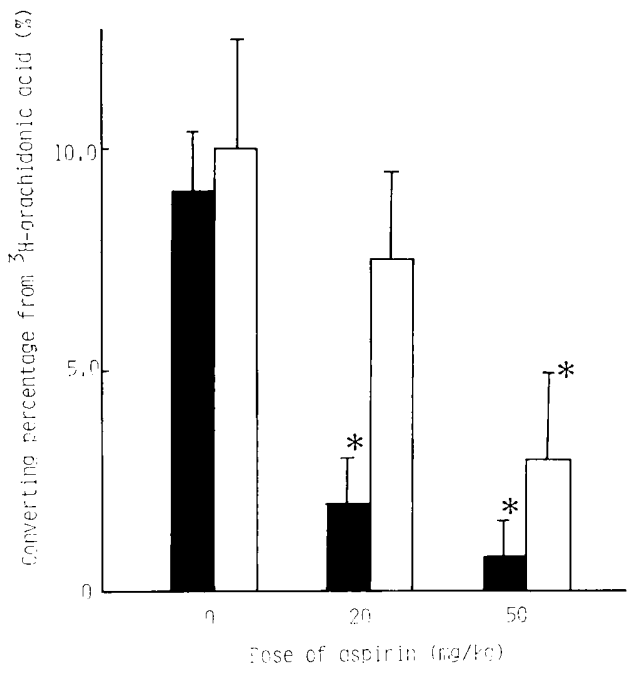

Fig. 2. Effect of aspirin on prostacyclin production from male and female rat aortae. Thoracic aortae were obtained from rats an hour after treatment with aspirin. $\mathrm{PGI}_{2}$ after incubation with arachidonic acid $(1.0 \mu \mathrm{g} / \mathrm{ml})$ was determined by the platelet aggregation method. Mean \pm S.D. $(n=8) . \quad{ }^{*} P<0.05$ : Significant difference from the control value for each sex, male, $\square$ : female. efficient in males than in females.

Figure 3 shows that aspirin inhibited the 6 -keto- $P \mathrm{GF}_{1 \boldsymbol{\alpha}}$ release from [ $\left.{ }^{3} \mathrm{H}\right]$-arachidonic acid used as a substrate. The results correspond with those from endogenous and exogenous arachidonic acid. Aspirin affected the 6-keto-PGF - $_{1 \infty}$ release in a dosedependent manner. This effect of aspirin was more effective in males than in females.

Effect of aspirin on $\mathrm{PGI}_{2}$ production with addition of $\mathrm{PGH}_{2}$ used as a substrate

Table 1 shows the effect of aspirin on the $\mathrm{PGI}_{2}$ production from exogenous $\mathrm{PGH}_{2}$. When arachidonic acid was used as the substrate, aspirin at a dose $50 \mathrm{mg} / \mathrm{kg} \mathrm{com-}$

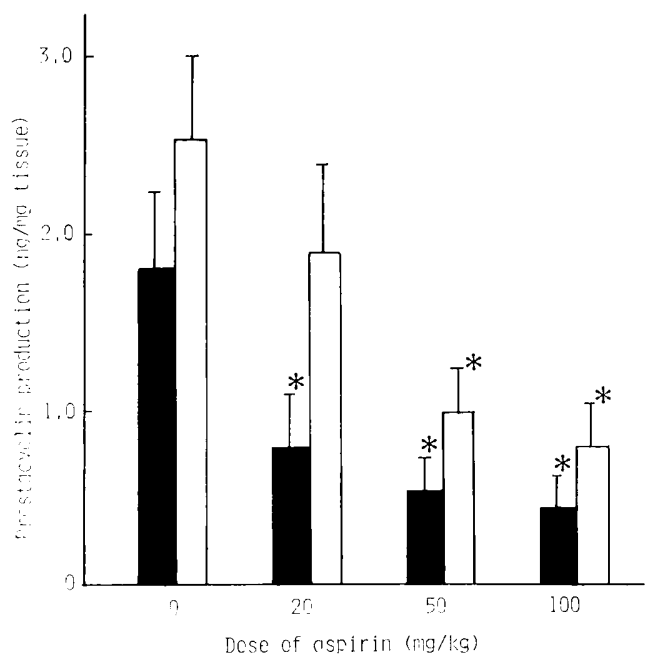

Fig. 3. Effect of aspirin on $\left[{ }^{3} \mathrm{H}\right]-6$-keto prostaglandin $F_{1^{\alpha}}$ production from $\left[{ }^{3} \mathrm{H}\right]$-arachidonic acid. The production of $\left[{ }^{3} \mathrm{H}\right]-6$-keto $P G F_{1}$ from $\left[{ }^{3} \mathrm{H}\right]$ arachidonic acid by male and female aortae was measured. Mean \pm S.D. $(n=5) .{ }^{*} P<0.05$ : Significant difference from the control value for each sex, male. $\square$ : female.

Table 1. Effect of aspirin on prostacyclin production with addition of prostagladin $\mathrm{H}_{2}$ as a substrate

\begin{tabular}{|c|c|c|}
\hline & & $\mathrm{PGl}_{2}$ production ( $\mathrm{ng} / \mathrm{mg}$ tissue $)^{*}$ \\
\hline & Control & Aspirin $(50 \mathrm{mg} / \mathrm{kg})$ \\
\hline Male & $0.23 \pm 0.07$ & $0.26 \pm 0.09$ \\
\hline Female & $0.25 \pm 0.03$ & $0.26 \pm 0.05$ \\
\hline
\end{tabular}

*Mean \pm S.D. $(n=6) . \quad \mathrm{PGI}_{2}$ was measured after incubation with $\mathrm{PGH}_{2}(0.5 \mu \mathrm{g} / \mathrm{ml})$ by the platelet aggregation method. 
pletely inhibited the $\mathrm{PGI}_{2}$ production of rat aorta in both sexes. However, when $\mathrm{PGH}_{2}$ was added as the substrate, aspirin had no influence on the $P G I_{2}$ production.

\section{Effect of aspirin in vitro}

Figure 4 shows that the $\mathrm{PGI}_{2}$ production is inhibited by aspirin in vitro. In male rats, aspirin inhibited the $\mathrm{PGI}_{2}$ production at 4.0 $\mu \mathrm{g} / \mathrm{ml}, 61.0 \pm 16.7 \%$; at $6.0 \mu \mathrm{g} / \mathrm{ml}, 32.6 \pm$ $13.7 \%$; and at $10.0 \mu \mathrm{g} / \mathrm{ml}, 19.4 \pm 10.5 \%$. In female rats, aspirin at $4.0 \mu \mathrm{g} / \mathrm{ml}$ did not inhibit th $\mathrm{PGI}_{2}$ production, and aspirin at $6.0 \mu \mathrm{g} / \mathrm{ml}$ inhibited the $\mathrm{PGI}_{2}$ production $(56.8 \pm 15.0 \%)$. There was a sex difference in the effect of aspirin at 4.0,6.0 and $10.0 \mathrm{~kg} / \mathrm{ml}$ on the $\mathrm{PGI}_{2}$ production in vitro.

Influence of gonadectomy and sex hormones

Table 2 shows the influence hormones and gonadectomy on $\mathrm{PGI}_{2}$ production and the effect of aspirin.

i) Change in $\mathrm{PGI}_{2}$ production by gonadectomy: In castrated male rats, aspirin showed a tendency to increase the $\mathrm{PGI}_{2}$ production. The inhibitory effect of aspirin on the $\mathrm{PGI}_{2}$ production was weaker in castrated male rats than in intact male rats. In ovariectomized female rats, the effect of aspirin was enhanced, and the amount of the produced $\mathrm{PGI}_{2}$ in ovariectomized female rats was the same as that in intact male rats.

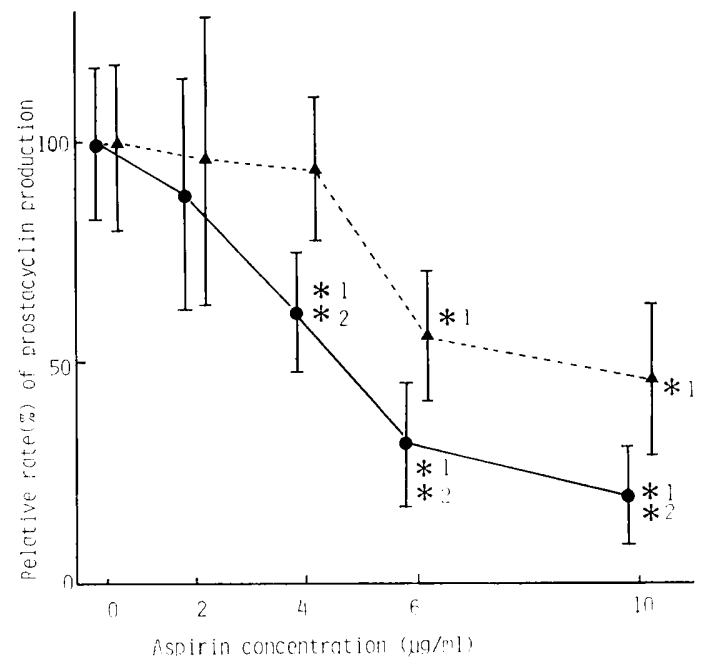

Fig. 4. Effect of aspirin on prostacyclin production from male and female rat aortae in vitro. Thoracic aortae were preincubated with aspirin and then were iricubated in Tris $\mathrm{HCl}$ buffer. $\mathrm{PGI}_{2}$ was measured as described under "Materials and Methods". Mean \pm S.D. $(n=5) .{ }^{* 1}$ : Significant difference from the control value for each sex $(P<0.05)$, *2: Significant difference from female value $(P<0.05)$. Each value is expressed as the relative rate with respect to the control for each sex. male, female.

Table 2. Change in prostacyclin production by gonadectomy and sex hormone treatment

\begin{tabular}{|c|c|c|c|c|c|}
\hline & & & & $\mathrm{PGI}_{2}$ production ( $\mathrm{n}$ & sue) \\
\hline & & Control & & ASA -20 & ASA- 50 \\
\hline \multirow[t]{3}{*}{-} & -- & -- $\quad-\quad \quad-$ & & $\ldots$ & \\
\hline & 1 & $0.71 \pm 0.18$ & & $0.38 \pm 0.12^{* 1}$ & $0.19 \pm 0.06^{* 1}$ \\
\hline & $1+E$ & $0.92 \pm 0.15$ & & $0.67 \pm 0.19$ & $0.30 \pm 0.15^{* 1}$ \\
\hline \multirow[t]{4}{*}{ Male } & $1+T$ & $0.64 \pm 0.09$ & & $0.22 \pm 0.15^{* 1}$ & - \\
\hline & C & $0.77 \pm 0.13$ & & $0.65 \pm 0.15$ & $0.32 \pm 0.14^{* 1}$ \\
\hline & $C+E$ & $0.97 \pm 0.20^{* 2}$ & & $0.92 \pm 0.11$ & $0.98 \pm 0.17$ \\
\hline & $\mathrm{C}+\mathrm{T}$ & $0.64 \pm 0.22$ & & $0.43 \pm 0.12$ & $\longrightarrow$ \\
\hline \multirow[t]{3}{*}{-} & - & $\ldots$ & $\cdots$ & $-\infty \quad$ & $-\quad-\quad$ \\
\hline & 1 & $0.88 \pm 0.25$ & & $0.63 \pm 0.22$ & $0.36 \pm 0.16^{* 1}$ \\
\hline & $1+E$ & $0.97 \pm 0.25$ & & $0.80 \pm 0.20$ & $\longrightarrow$ \\
\hline \multirow[t]{4}{*}{ Female } & $1+T$ & $0.80 \pm 0.17$ & & $0.34 \pm 0.14^{* 1}$ & $\longrightarrow$ \\
\hline & 0 & $0.79 \pm 0.23$ & & $0.39 \pm 0.27$ & $0.18 \pm 0.10^{* 1}$ \\
\hline & $O+E$ & $0.96 \pm 0.20$ & & $0.82 \pm 0.22$ & $0.81 \pm 0.19$ \\
\hline & $\mathrm{O}+\mathrm{T}$ & $0.79 \pm 0.17$ & & $0.39 \pm 0.19 * 1$ & $\longrightarrow$ \\
\hline
\end{tabular}

I. Intact; C. Castration; O, Ovariectomy: E, Estradiol $(10 \mu \mathrm{g} / \mathrm{kg}):$, Testosterone $(5.0 \mathrm{mg} / \mathrm{kg}):$ - Not tested: ASA, Aspirin. The values of the mean \pm S.D. $(n=5)$ are given. *1: Significant difference from the control value for each sex $(P<0.05)$. ${ }^{* 2}$ : Significant difference from the intact male control value $(P<0.05)$. 
ii) Change in $\mathrm{PGI}_{2}$ production by treatment with estradiol: To study the influence of sex hormones on $\mathrm{PGI}_{2}$ production, estradiol was administered. Doses of 10,50 and $100 \mu \mathrm{g} / \mathrm{kg}$ were chosen. The influence of estradiol was similar among these three doses.

In the intact and castrated male rats treated with estradiol, the $\mathrm{PGI}_{2}$ production tended to increase. In the castrated male rats treated with estradiol, aspirin did not decrease the $\mathrm{PGI}_{2}$ production, but in the intact male rats with estradiol, aspirin showed a tendency to decrease the $\mathrm{PGI}_{2}$ production. In the intact and ovariectomized female rats treated with estradiol, the $\mathrm{PGI}_{2}$ production tended to increase, and the effect of aspirin was reduced.

iii) Change in $\mathrm{PGI}_{2}$ production by treatment with testosterone: To study the influence of testosterone on $\mathrm{PGI}_{2}$ production, rats were administered with testosterone $(2.0,5.0$ and $10.0 \mathrm{mg} / \mathrm{kg}$ ). The influence of testosterone was similar at 5.0 and $10.0 \mathrm{mg} / \mathrm{kg}$, but it was weaker at $2.0 \mathrm{mg} / \mathrm{kg}$

In the intact male rats treated with testosterone, the effect of aspirin on the $\mathrm{PGI}_{2}$ production was similar to that in intact male rats. However, in the castrated male rats with testosterone, aspirin did not significantly decrease the $\mathrm{PGI}_{2}$ production. In the intact and ovariectomized female rats treated with testosterone, the effect of aspirin on the $\mathrm{PGI}_{2}$ production was enhanced and similar to that in intact male rats.

Interaction of aspirin with sex hormones in vitro

Interaction of aspirin with sex hormones was examined in vitro. It is shown that testosterone and estradiol did not influence the effect of aspirin directly.

\section{Discussion}

It is known that $P \mathrm{GI}_{2}$ is the main product in rat aorta and an important material in thrombosis. Some investigators have studied the $\mathrm{PGI}_{2}$ production in rat aorta. Pomerantz et al. (15) reported the sex hormonal modification of 6 -keto- $\mathrm{PGF}_{1 \propto}$ release by intact and gonadectomized rats. Their results showed that more 6 -keto-PGF ${ }_{1 \alpha}$ was release by male rat aorta than by female rat aorta, estradiol decreased 6-keto-PGF $F_{1 a}$, and testosterone had no influence on 6-keto-PGF $F_{1 \alpha}$ release by rat aorta. On the other hand, Chang et al. and Nakao et al. (8-10) reported that estradiol increased the $\mathrm{PGI}_{2}$ production in rat aorta, and testosterone decreased the $\mathrm{PGI}_{2}$ production in the cultured smooth muscle cells of rat aorta. These two conclusions contradicted each other. However, sex hormones must have some influence on the $\mathrm{PGI}_{2}$ production in rat aorta. In this study, the effect of aspirin on the $\mathrm{PGI}_{2}$ production of rat aorta was examined in intact, gonadectomized and sex hormone treated rats.

In intact rats, there was no significant sex difference in the $\mathrm{PGI}_{2}$ production in rat aorta when endogenous and exogenous arachidonic acid were used as substates, but the $\mathrm{PGI}_{2}$ production in females was slightly more than in males. Aspirin decreased the $\mathrm{PGI}_{2}$ production dose-dependently, and the effect was more pronounced in males than in females.

Neither the significant sex difference nor the inhibitory effect of aspirin on $\mathrm{PGI}_{2}$ production was found in control rat aorta added with $\mathrm{PGH}_{2}$ as a substrate. These results show that aspirin does not affect the $\mathrm{PGI}_{2}$ synthesis process from $\mathrm{PGH}_{2}$. The site for the effect of aspirin seems to be in the course of the conversion of arachidonic acid to $\mathrm{PGH}_{2}$.

It is doubtful that a difference of the pharmacokinetics of aspirin causes the sex difference in $\mathrm{PGI}_{2}$ production. After 20 or $50 \mathrm{mg} / \mathrm{kg}$ of aspirin was administered to male and female rats, there was no sex difference in the maximum serum concentration, the time of the maximum serum concentration and the AUC of salicylic acid.

On the other hand, when the effect of aspirin was examined in vitro, aspirin significantly inhibited the $\mathrm{PGI}_{2}$ production at a lower concentration in male rats, but in female rats, high concentrations of aspirin were necessary to inhibit the $\left.P G\right|_{2}$ production. A significant sex difference was found in the effect of aspirin on $\mathrm{PGI}_{2}$ production. Aspirin affected the $\mathrm{PGI}_{2}$ production not only in vivo but also in vitro. Therefore, it is suggested that the sex difference in the effect of aspirin 
is not due to a process involving the pharmacokinetics of aspirin, but is a process involving the $\mathrm{PGI}_{2}$ production.

In sex hormone treated rats, estradiol tended to increase the $\mathrm{PGI}_{2}$ production in rat aorta, but testosterone tended to decrease it. In the male rats treated with estradiol, the effect of aspirin was weaker in castrated rats than in intact rats. It seems that in intact rats, endogenous testosterone may influence the action of exogenous estradiol in the process of $\mathrm{PGI}_{2}$ production. Accordingly, it seems that aspirin strongly inhibited the $\mathrm{PGI}_{2}$ production in the intact male rats treated with estradiol. Estradiol tended to increase the $\mathrm{PGI}_{2}$ production and suppress the effect of aspirin in intact and ovariectomized female rats. Moreover, it was proven by Chang et al. (8) that estradiol stimulated cyclooxygenase in the cultured smooth muscle of rat aorta Their results agree with the results of this report. It is suggested from the results in this study that the low concentration of estradiol $(10 / \mathrm{kg} / \mathrm{kg})$ must have affected the process of $\mathrm{PGI}_{2}$ production and reduced the effect of aspirin.

In the male rats treated with testosterone. the $\mathrm{PGI}_{2}$ production tended to decrease, but the effect of aspirin was different between castrated rats and intact rats. Castration weakened the effect of aspirin on the process of $\mathrm{PGI}_{2}$ production. So, it is suggested that endogenous testosterone plays an important role in the regulatory system for $\mathrm{PGI}_{2}$ production. Nakao et al. (10) also reported that testosterone suppressed the $\mathrm{PGI}_{2}$ production in cultured smooth muscle cells of rat aorta. This effect of testosterone in contrary to that of estradiol, and these two sex hormones must regulate the $\mathrm{PGI}_{2}$ production in the body.

There is a possibility that aspirin may interact with sex hormones directly, but in vitro, the effect of aspirin on the $\mathrm{PGI}_{2}$ production did not differ significantly in the presence or absence of hormone. So, it seems that sex hormones do not directly influence the effect of aspirin on the $\mathrm{PGI}_{2}$ production.

The inhibitory effect of aspirin on the $\mathrm{PGI}_{2}$ production was enhanced by testosterone treatment, but weakened by estradiol treat- ment. In female rats, it is likely that the capacity for $\mathrm{PGI}_{2}$ production is latently elevated by estradiol and the effect of aspirin consequently weakened. However, in male rats, it is likely that the capacity for $\mathrm{PGI}_{2}$ production is reduced or not influenced by testosterone, and the effect of aspirin is strongly enhanced. It has not yet been reported whether testosterone suppresses cyclooxygenase.

These results suggest that the sex difference in the effect of aspirin is regulated by sex hormones. This must be one of the main reasons that the effect of aspirin on the $\mathrm{PGI}_{2}$ production in rat aorta is stronger in males than in females. Further studies on the enzyme level are to be carried out by the authors.

Acknowledgement: The authors wish to thank Ono Yakuhin Kogyo Co. Ltd., Osaka, Japan for the generous gifts of standard $\mathrm{PGI}_{2}$ and $\mathrm{PGH}_{2}$.

\section{References}

1 Harris, W.H., Saizman, E.W., Athanasoulis, C.A., Waltman, A.C. and Desanctics, R.W.: Aspirin prophylaxis or venous thromboembolism after total hip replacement. N. Engl. J. Med. 297, 1246-1249 (1977)

2 The Canadian Cooperative Study Group: A randomized trial of aspirin and sulfinpyrasone in threatened stroke. N. Engl. J. Med. 299, 53-59 (1978)

3 Harter, H.R., Burch, J.W., Majerus, P.W., Stanfird, N., Delez, J.A., Anderson, C.B. and Weerts, C.A.: Prevention of thrombosis in patients on hemodialysis by low-dose aspirin. N. Engl. J. Med. 301, 577-579 (1979)

4 Kelton, J.G., Hirsh, J., Carter, C.J. and Buchanan, M.R.: Sex differences in the antithrombotic effects of aspirin. Blood 52, 1072-1076 (1978)

5 Vane, J.R.: Possible action through inhibition of synthesis of prostaglandins. Nature 231, 232 235 (1.971)

6 Roth, G.J. and Maferus, P.W.: The mechanism of the effect of aspirin on human platelets. J. Clin. invest. 56, 624-632 (1975)

7 Moncada, S., Higgs, E.A. and Vane, J.R.: Human arterial and venous tissue prostacyclin (prostaglandin $X)$, a potent inhibitor of platelet aggregetion. Lancet i, 18-20 (1977)

8 Chang, W.C., Nakao, J., Orimo, H. and Murota, S.: Stimulation of prostaglandin cyclooxygenase. and prostacyclin synthetase activities by estradiol in rat aortic smooth muscle cells. Biochim. 
Biophys. Acta 620, 472-482 (1980)

9 Chang, V.C., Nakao, J., Neichi, T., Orimo, H. and Murota, S.: Effect of estradiol on the metabolism of arachidonic acid by aortas and platelets in rats. Biochim. Biophys. Acta 664, 291-297 (1981)

10 Nakao, J., Chang, W.C., Murota, S. and Orimo, S.: Testosterone inhibits prostacyclin production by rat aortic smooth muscle cells in culture. Atherosclerosis 39, 203-209 (1981)

11 Harada, Y., Tanaka, K. and Katori, M.: Acceleration of endogeneous $P \mathrm{Pl}_{2}$ generation from isolated rat aorta by MK-447. Japan. J. Pharmacol. 31, 845-848 (1981)

12 Harada, Y., Tanaka, K. and Katori, M.: Decreased activity of prostaglandin endoperoxide syn- thetase in prostaglandin $\mathrm{I}_{2}$ (prostacyclin) biosynthesis from arachidonic acid in isolated rat aortae. Proc. Japan. Acad. 56B, 394-398 (1980)

13 Ellis, E.F., Wright, K.F., Jones, P.S., Richardson, D.W. and Ellis, C.K.: Effect of oral aspirin dose on platelet aggregation and vascular prostacyclin $\left(\mathrm{PGI}_{2}\right)$ synthesis in human and rabbits. J. Cardiovasc. Pharmacol. 2, 387-397 (1980)

14 Sun, F.F., Chapman, J.P. and McGuire, J.C.: Metabolism of prostaglandin endoperoxide in animal tissues. Prostaglandins 14, 1055-1074 (1977)

15 Pomerantz, K., Maddox, Y., Maggi, F., Ramey, E. and Ramwell, P.: Sex and hormonal modification of 6-keto-PGF 1 r release by rat aorta. Life Sci. 27, 1233-1236 (1980) 